\title{
ANALISIS RELIABILITY CENTERED MAINTENANCE (RCM) PADA ALAT BONGKAR MUAT RUBBER TYRE GANTRY CRANE (RTGC) DI PT XXX
}

\author{
Rahmatulloh $^{1}$, Suharto $^{1}$, Riana Septiani ${ }^{1}$ \\ ${ }^{1}$ Prodi Teknik Industri, Universitas Tulang Bawang \\ Jalan Gajah Mada 34 Kota Baru, Bandar Lampung \\ *Penulis Korespondensi: rahmatth12@gmail.com
}

\begin{abstract}
The loading and Unloading operational activities in port often run into obstacle, because happened malfunction occurrence of the equipment used. Failure to operate the equipment has resulted in downtime decreased of company productivity. Therefore, a system is needed maintenance of planning in order to produce the equipment that can be operated optimally. This research was choosen the company $P T . X X X$ which is a company that enganged in the field maintenance of equipments port operational (quayside container crane, rubber tyre gantry crane, gantry luffing crane, and others) the place where the equipment maintenance system, especially the rubber tyre gantry crane (RTGC) which has been done are still a breakdown maintenance and corrective maintenance. The aim of this research is to analyze by method of reliability centered maintenance $(R C M)$ to able to determined the optimal maintenance and it can be predict steps to overcome the damage that might will happen in the next period based on existing data. From data processing and analysis was obtained that the components most frequently damaged on the equipment of $R T G C$, cause of failure, selection decision and recommendations for maintenance systems are based on Reliability Centered Maintenance (RCM).
\end{abstract}

Keywords: Failure, Maintenance, Rubber Tyre Gantry Crane (RTGC), Reliability Centered Maintenance (RCM), Planning.

\section{Pendahuluan}

Dunia industri tak lepas dari adanya sebuah mesin atau alat dalam memproduksi barang. Mesin merupakan aset fisik agar perusahaan dapat terus produktif maka mesin memerlukan perawatan. Dalam mendukung beroperasinya suatu sistem berjalan secara lancar dan sesuai yang dikehendaki maka kegiatan perawatan mempunyai peranan penting. Kegiatan perawatan juga dapat meminimalkan biaya atau kerugian yang timbul akibat kerusakan mesin (Utomo, 2018).

PT. XXX adalah anak perusahaan dari PELINDO II atau nama lainnya Indonesia Port Corporation (IPC) yang merupakan salah satu perusahaan BUMN yang bergerak dibidang kepelabuhan. PT. XXX adalah perusahaan yang telah dipercaya untuk mengelola alat-alat bongkar muat pelabuhan yang berada di 9 lokasi di Indonesia yang salah satunya berada di pelabuhan panjang, Bandar Lampung.

Dengan semakin meningkatnya produksi dari bongkar muat dipelabuhan (ekspor dan impor barang), maka IPC harus dapat meningkatkan efektivitas dan efisiensi dalam proses bongkar muatnya. Salah satunya menuntut PT. Jasa Peralatan Pelabuhuan Indonesia sebagai pengelola dan pemeliharaan alat bongkar muat pelabuhan untuk meningkatkan keandalan alat bongkar muat seoptimal mungkin dalam mendukung proses operasional berlangsung.

Rubber Tyre Gantry Crane (RTGC) merupakan salah satu alat bantu bongkar muat yang beroda karet (ban), 
dalam dunia kepelabuhan RTGC digunakan untuk memindahkan kontainer yang berada truk ketempat penampungan atau sebaliknya.

Alat bongkar muat RTGC di pelabuhan panjang ada 5 unit yaitu : 3 unit RTGC Bukaka dengan kapasitas angkut 28 ton dan 2 unit RTGC Noell dengan kapasitas angkut 30 ton. Pada tabel 1.1 akan menampilkan tentang data dari alat bongkat muat RTGC yang beroperasi di pelabuhan panjang.

Berikut ini adalah data unit alatalat bongkar muat RTGC yang ada di pelabuhan panjang yang dikelola oleh PT. XXX tahun 2019 yang beroperasi di area terminal peti kemas panjang dapat dilihat dalam tabel 1.1.

\begin{tabular}{cccc}
\hline No & $\begin{array}{c}\text { Nama } \\
\text { Alat }\end{array}$ & Product & $\begin{array}{c}\text { Kode } \\
\text { Unit }\end{array}$ \\
\hline 1 & $R T G C$ & Bukaka & RTGC 01 \\
2 & $R T G C$ & Bukaka & RTGC 02 \\
3 & $R T G C$ & Bukaka & RTGC 03 \\
4 & $R T G C$ & Noell & RTGC 04 \\
5 & $R T G C$ & Noell & RTGC 05 \\
\hline
\end{tabular}

Alat bongkar muat RTGC yang dikelola PT. XXX tergolong mesin yang setiap hari melakukan aktivitas operasional. Dalam proses operasi dari alat bongkar muat RTGC pasti mengalami kerusakan yang harus dilakukan perbaikan.

Sistem perawatan yang dilakukan oleh PT. XXX saat ini menggunakan sistem breakdown maintenance dan preventive maintenance. Menurut Ansori dan Mustajib (2013), breakdown maintenance merupakan kegiatan yang dilakukan setelah terjadinya kerusakan, sedangkan preventive maintenance adalah kegiatan pemeliharaan dan perawatan yang dilakukan untuk mencegah timbulnya kerusakan yang tidak terduga.

Namun dalam pelaksanaannya dilapangan terdapat berbagai kendala yang mengakibatkan perawatan tersebut belum efektif. Misalnya tidak ada penjadwalan perawatan komponen yang teratur menyebab mesin akan breakdown dan mengganggu jadwal operasi dari alat bongkar muat RTGC.

Kemudian sistem perawatan perbaikan kerusakan yang terjadi pada alat RTGC tidak pernah dilakukan studi lebih lanjut tentang akar penyebab kerusakan, sehingga kerusakan yang sama tidak dapat diantisipasi hal ini merupakan masalah dalam penelitian ini.

Failure mode and Effect Analysis (FMEA) akan berguna dalam melakukan mengidentifikasi komponen yang mengalami kerusakan kemudian dapat dianalisis penyebab dan efek kegagalan dari kerusakan yang terjadi. Menurut Daydem (2003), FMEA adalah proses yang sistematis untuk mengidentifikasi potensi kegagalan dan dampak dari kegagalan sehingga dampak bisa dikurangi.

\section{Metode Penelitian}

\section{Waktu dan Tempat Penelitian}

Dalam penelitian ini, peneliti memilih di perusahaan peralatan bongkar muat pelabuhan (perusahaan alat berat). Area yang akan diteliti oleh peneliti yaitu pada area terminal peti kemas dimana terdapat alat yang di gunakan untuk melakukan proses bongkar muat kontainer. Untuk waktu penelitian penulis melakukan penelitian selama 1 (satu) bulan, dimulai pada tanggal 1 Januari 2020 sampai dengan tanggal 31 Januari 2020.

\section{Pengolahan Data}

Berdasarkan data-data yang diperoleh dari perusahaan, selanjutnya penulis melakukan pengolahan data dan perhitungan untuk menunjang penelitian tersebut. Pengolahan data yang dilakukan sebagai berikut:

1. Perhitungan Failure Modes and Effect Analyze (FMEA)

2. Perhitungan Mean Time to Failure (MTTF)

3. Perhitungan Mean Time to Repair (MTTR)

4. Perhitungan Parameter TTF dan TTR Analisis Data 
Setelah pengolahan data dilakukan, maka tahap selanjutnya yaitu menganalisa terhadap hasil perhitungan MTTF, MTTR, dan Interval Waktu Perawatan mesin.

\section{Hasil dan Pembahasan}

Perhitungan Failure Mode and Effect Analyze (FMEA)

RTGC memiliki 6 bagian sistem yang memiliki fungsi masing-masing namun saling keterkaitan dalam suatu proses bongkar muat, adapun datanya klasifikasi downtime sebagai berikut:

\begin{tabular}{lc}
\hline Klasifikasi & 020-RTG-05 \\
\hline Electrical & 1 \\
\hline Engine & 3 \\
\hline Gantry & 10 \\
Hoist & 6 \\
Spreader & 3 \\
\hline Trolley & 2 \\
\hline Grand Total & 25 \\
\hline
\end{tabular}

Dari tabel diatas dapat dilihat bahwa RTGC paling sering terjadi kegagalan fungsi pada sistem gantry dengan total 10 kali kejadian, Gantry memiliki komponen penggerak yang beragam mulai dari motor listrik, ban, pin lock/unlock, hydraulic cross, dan banyak lagi. Namun setiap terjadi kegagalan dari komponen akan berpengaruh pada fungsional alat secara keseluruhan atau pada sistem gantry. Selanjutnya akan ditentukan nilai RPN nya.

Dalam perhitungan ini menggunakan nilai peringkat yang mana menggambarkan kerusakan-kerusakan yang terjadi pada alat saat proses operasional berlangsung. Berdasarkan analisis melalui FMEA maka didapatkan nilai risk priority number (RPN) masingmasing komponen yang didaptkan dari nilai peringkat severity, occurance dan detection. Dapat diketahui dari tabel Failure Mode and Effect Analysis (FMEA) bahwa nilai total RPN tertinggi terdapat pada komponen yaitu sensor pin lock/unlock dengan nilai RPN 204. Dari hasil perhitungan FMEA tersebut selanjutnya akan dilakukan tindakan perawatan menggunakan metode Reliability Centered Maintenance. 


\begin{tabular}{|c|c|c|c|c|c|c|c|c|c|}
\hline \multirow{2}{*}{\multicolumn{3}{|c|}{ FMEA Worksheet }} & \multicolumn{7}{|c|}{ SISTEM : RUBBER TYRE GANTRY CRANE 05} \\
\hline & & & & & SUB SISTEM : & GANTRY & & & \\
\hline Part/Process & Function & Potential Failure Mode & Potential Effect Of Failure & $\operatorname{Sev}(1-10)$ & Potential Cause of Failure & $O c c(1-10)$ & Current Control & $\operatorname{Det}(1-10)$ & $R P N$ \\
\hline \multirow{3}{*}{ Motor Gantry } & \multirow{3}{*}{ Penggerak Utama } & \multirow{2}{*}{ Kampas Brake Gantry } & $\begin{array}{c}\text { Tidak bisa berhenti dengan } \\
\text { tepat }\end{array}$ & 3 & $\begin{array}{c}\text { Usia pemakaian kampas } \\
\text { telah habis }\end{array}$ & 1 & $\begin{array}{c}\text { Pengecekan kampas secara } \\
\text { rutin }\end{array}$ & 5 & 15 \\
\hline & & & $\begin{array}{c}\text { Roda gantry tidak } \\
\text { stabil/bergerak-gerak }\end{array}$ & 3 & Kampas kurang disetting & 1 & $\begin{array}{l}\text { Pengecekan baut setting } \\
\text { kampas secara rutin }\end{array}$ & 4 & 12 \\
\hline & & Koil Brake & $\begin{array}{l}\text { mengakibatkan putaran } \\
\text { motor berat }\end{array}$ & 4 & koil brake kotor & 1 & mengontrol koil brake & 4 & 16 \\
\hline \multirow{3}{*}{ Hydraulic Cross } & & & & & & & & TOTAL RPN & 43 \\
\hline & \multirow[t]{2}{*}{ Memutar Poros Roda Gantry } & kebocoran Pada Seal & $\begin{array}{c}\text { Sistem tidak bekerja } \\
\text { dengan baik atau gerakan } \\
\text { cross lambat }\end{array}$ & 3 & $\begin{array}{l}\text { Kotoran pada piston } \\
\text { hydraulic }\end{array}$ & 1 & $\begin{array}{l}\text { Pengecekan kinerja } \\
\text { hydraulic cross }\end{array}$ & 4 & 12 \\
\hline & & kebocoran Pada Hose & $\begin{array}{l}\text { Tidak bisa melakukan } \\
\text { crossing }\end{array}$ & 3 & fleksibilitas hose kurang & 1 & $\begin{array}{c}\text { Pengecekan hose secara } \\
\text { rutin }\end{array}$ & 5 & 15 \\
\hline & & & & & & & & & 27 \\
\hline \multirow{2}{*}{ Pin Lock/Unlock } & \multirow{2}{*}{ Pengunci Roda Gantry } & kebocoran Pada Seal & $\begin{array}{c}\text { Pin tidak terkunci dengan } \\
\text { maksimal }\end{array}$ & 3 & $\begin{array}{l}\text { Kotoran pada piston } \\
\text { hyraulic }\end{array}$ & 1 & $\begin{array}{l}\text { Pengecekan kinerja pin } \\
\text { lock/unlock }\end{array}$ & 4 & 12 \\
\hline & & Kebocoran Pada Hose & $\begin{array}{l}\text { Tidak bisa melakukan } \\
\text { crossing }\end{array}$ & 3 & fleksibilitas hose kurang & 1 & $\begin{array}{c}\text { Pengecekan hose secara } \\
\text { rutin }\end{array}$ & 5 & 15 \\
\hline \multirow{4}{*}{ Sensor Cross } & & & & & & & & TOTAL RPN & 27 \\
\hline & \multirow{3}{*}{ Pembaca Status Cross } & Sensor Rusak & Tidak dapat beroperasi & 6 & $\begin{array}{c}\text { usia pemakaian sensor } \\
\text { habis }\end{array}$ & 1 & $\begin{array}{c}\text { Pengecekan usia } \\
\text { pemakaian }\end{array}$ & 7 & 42 \\
\hline & & Socket Longgar & Sensor telat memberi status & 3 & Getaran saat gantry & 2 & $\begin{array}{c}\text { mengontrol sensor secara } \\
\text { rutin }\end{array}$ & 8 & 48 \\
\hline & & Tuas 90 derajat & Tuas tertabrak & 6 & komponen tuas tidak orisinil & 2 & Pengecekan tuas & 5 & 60 \\
\hline \multirow{4}{*}{ Sensor Pin Lock/Unlock } & & & & & & & & TOTAL RPN & 150 \\
\hline & \multirow{3}{*}{ Pembaca Status Pin Lock/Unlock } & Tuas Sensor Tidak Pas & $\begin{array}{l}\text { sensor tidak menerima } \\
\text { status }\end{array}$ & 6 & Baut pada tuas longgar & 3 & $\begin{array}{c}\text { Mengontrol baut pada tuas } \\
\text { sensor }\end{array}$ & 5 & 90 \\
\hline & & Sensor Rusak & Tidak dapat beroperasi & 6 & Usia pemakaian habis & 1 & $\begin{array}{c}\text { Pengecekan usia } \\
\text { pemakaian } \\
\end{array}$ & 7 & 42 \\
\hline & & Socket Longgar & Sensor telat memberi status & 3 & Getaran saat gantry & 3 & $\begin{array}{c}\text { Mengontrol sensor saat } \\
\text { beroperasi }\end{array}$ & 8 & 72 \\
\hline \multirow{3}{*}{ Hydraulic Pump } & & & & & & & & TOTAL RPN & 204 \\
\hline & \multirow[t]{2}{*}{ Mensuplai Oli Hydraulic } & Selenoid Rusak & $\begin{array}{l}\text { Suplai oli hydraulic tidak } \\
\text { berjalan dengan baik }\end{array}$ & 7 & $\begin{array}{c}\text { Pengoperasian yang sudah } \\
\text { lama }\end{array}$ & 1 & $\begin{array}{c}\text { Pengecekan usia } \\
\text { pemakaian dan kontrol } \\
\text { rutin }\end{array}$ & 6 & 42 \\
\hline & & Main Valve Kotor & $\begin{array}{c}\text { Suplai oli hydraulic tidak } \\
\text { tersalurkan }\end{array}$ & 7 & $\begin{array}{l}\text { kualitas oli hyraulic yang } \\
\text { kotor }\end{array}$ & 1 & $\begin{array}{c}\text { Mengontrol penyaringan oli } \\
\text { hydraulic }\end{array}$ & 6 & 42 \\
\hline & & & & & & & & TOTAL RPN & 84 \\
\hline
\end{tabular}




\section{Perhitungan Reliability Centered \\ Maintenance (RCM) \\ Identifikasi Distribusi Untuk Selang \\ Waktu Kerusakan (Time To Failure)}

Untuk dapat menentukkan

distribusi yang sesuai untuk data waktu kerusakan TTF (Time to Failure), maka dilakukan perhitungan index of fit dari tiap distribusi tersebut. Dan pemilihan distribusi berdasarkan pada nilai index of fit yang terbesar dari masing-masing komponen. Hasil dari perhitungan masing-masing distribusi pada komponen sensor pin lock/unlock dengan index of fit yaitu diperoleh sebagai berikut.

\begin{tabular}{ccccc}
\hline $\begin{array}{c}\text { Nama } \\
\text { Komponen }\end{array}$ & $\begin{array}{c}\text { Distribusi } \\
\text { Eksponensial }\end{array}$ & $\begin{array}{c}\text { Index Of Fit } \\
\text { Nortribusi } \\
\text { Normal }\end{array}$ & $\begin{array}{c}\text { Distribusi } \\
\text { Lognormal }\end{array}$ & $\begin{array}{c}\text { Distribusi } \\
\text { Weidbull }\end{array}$ \\
\hline $\begin{array}{c}\text { Sensor Pin } \\
\text { Lock/Unlock }\end{array}$ & $-0,017$ & 0,000 & 1,000 & 0,019 \\
\hline
\end{tabular}

Setelah memperoleh index of fit dari setiap distribusi untuk komponen sensor pin lock/unlock, maka harus diuji dulu kesesuaiannya. Pengujian-pengujian yang digunakan adalah sebagai berikut : Sensor pin lock/unlock nilai index of fit terbesar yang diperoleh oleh komponen sensor pin lock/unlock adalah berdasarkan distribusi lognormal, maka uji kesesuaian yang digunakan adalah Kolmogorov-Smirnov test.

Setelah dilakukan perhitungan maka diketahui $\mathrm{D}_{1}=0.241$ dan $\mathrm{D}_{2}=0.760$ nilai terbesarlah yang diambil, dilihat nilai Uji statistik $D_{1}$ dan $D_{2}$ nilai yang terbesarnya adalah $\mathrm{D}_{2}$ dengan nilai 0.760 yang diperoleh dari nilai table kritis untuk Uji Normalitas Kolmogorov Smirnov. Sehingga: Dhitung $=0.760>$ $0.688=$ Dtabel (Tabel Kolgomorov Smirnov).

Maka dapat disimpulkan H0 ditolak dan $\mathrm{H} 1$ diterima, dikarenakan $\mathrm{H} 0$ ditolak maka data akan diuji kembali dengan data yang memiliki nilai index of fit terbesar selanjutnya yaitu distribusi weibull maka uji kesesuaian yang digunakan adalah Mann's.

Setelah dilakukan perhitungan maka diketahui nilai statistik dari $\mathrm{M}=$ $0,435<16,69=\mathrm{F}(0,01 ; 3 ; 4)=\mathrm{F}($ tabel $)$. Maka dapat disimpulkan $\mathrm{H} 0$ diterima dan H1 ditolak, maka data waktu Time To Failure (TTF) pada komponen sensor pin lock/unlock berdistribusi Weibull.

\section{Identifikasi Distribusi Untuk Selang Waktu Perbaikan (Time To Repaire)}

Untuk dapat menentukkan distribusi yang sesuai untuk data waktu kerusakan TTR (Time to Repaire), maka dilakukan perhitungan index of fit dari tiap distribusi tersebut. Dan pemilihan distribusi berdasarkan pada nilai index of fit yang terbesar dari masing-masing komponen.

Hasil dari perhitungan masingmasing distribusi pada komponen sensor pin lock/unlock dengan index of fit yaitu diperoleh sebagai berikut.

\begin{tabular}{ccccc}
\hline $\begin{array}{c}\text { Nama } \\
\text { Komponen }\end{array}$ & $\begin{array}{c}\text { Distribusi } \\
\text { Eksponensial }\end{array}$ & $\begin{array}{c}\text { Distribusi } \\
\text { Normal }\end{array}$ & $\begin{array}{c}\text { Distribusi } \\
\text { Lognormal }\end{array}$ & $\begin{array}{c}\text { Distribusi } \\
\text { Weidbull }\end{array}$ \\
\hline $\begin{array}{c}\text { Sensor Pin } \\
\text { Lock/Unlock }\end{array}$ & -0.552 & 0.000 & 1.000 & -0.799 \\
\hline
\end{tabular}

Setelah memperoleh index of fit dari setiap distribusi untuk komponen sensor pin lock/unlock, maka harus diuji dulu kesesuaiannya. Pengujianpengujian yang digunakan adalah sebagai berikut : 
Sensor pin lock/unlock nilai index of fit terbesar yang diperoleh oleh komponen sensor pin lock/unlock adalah berdasarkan distribusi lognormal, maka uji kesesuaian yang digunakan adalah Kolmogorov-Smirnov test.

Setelah dilakukan perhitungan maka diketahui $\mathrm{D}_{1}=0.916$ dan $\mathrm{D}_{2}=0.084$ nilai terbesarlah yang diambil, dilihat nilai Uji statistik $D_{1}$ dan $D_{2}$ nilai yang terbesarnya adalah $\mathrm{D}_{2}$ dengan nilai 0.916 yang diperoleh dari nilai table kritis untuk Uji Normalitas Kolmogorov Smirnov. Sehingga: Dhitung $=0.9160>$ $0.627=$ Dtabel $($ Tabel Kolgomorov Smirnov).

Maka dapat disimpulkan $\mathrm{H} 0$ ditolak dan $\mathrm{H} 1$ diterima, dikarenakan $\mathrm{H} 0$ ditolak maka data akan diuji kembali dengan data yang memiliki nilai index of fit terbesar selanjutnya yaitu distribusi eksponensial.

Setelah dilakukan perhitungan maka diketahui $\mathrm{X}_{\alpha-1}^{2}(0,99)=0,2971<\mathrm{B}$ $=0,364<11,143=X_{\alpha}^{2}(0,01)$, maka disimpulkan H0 diterima dan H1 ditolak. Maka nilai TTR dari sensor pin lock/unlock berdistribusi eksponensial.

\section{Penentuan Parameter, MTTF dan MTTR Untuk Komponen Sensor Pin Lock/Unlock}

Setelah dilakukan uji terhadap distribusi-distribusi tersebut, perhitungan selanjutnya yaitu perhitungan parameter. Perhitungan parameter untuk komponen sensor pin lock/unlock yang berdistribusi weibull dan distribusi eksponensial, dengan hasil pada tabel berikut:

\begin{tabular}{cccccccc}
\hline Jenis & \multicolumn{8}{c}{ Parameter } \\
Distribusi & $\beta$ & $\mathrm{A}$ & $\Theta$ & $\lambda$ & Index Of Fit & MTTF & \multirow{2}{*}{ MTTR } \\
\hline Weibull & 2,500 & $-15,748$ & 543,828 & & 0,019 & 482,517 & \\
Eksponesial & & & & 3,333 & $-0,552$ & & 0,300 \\
\hline
\end{tabular}

\section{Perhitungan Interval Waktu Perawatan}

Untuk menentukan interval waktu pemeriksaan komponen sensor pin lock/unlock berdasarkan waktu operasional yang ada dilakukan dengan tahap-tahap berikut ini :

1. Rata-rata kerja perbulan (i)

Hari kerja perbulan $=30$

Jam kerja tiap hari $=21$

Rata-rata jam kerja perbulan (i) $=30$ x $21=630[\ln (630)=6,446]$

2. Rata-rata kerusakan $(\mathrm{k})=5 / 4=1.25$

3. Waktu rata-rata kerusakan $(\mu)=6,108$

4. Frekuensi perawatan optimal $(n)=$ $\sqrt{\frac{k * i}{\mu}}=\sqrt{\frac{1.25 * 6,446}{6,108}}=1,148 / 1 \mathrm{kali}$ perbulan

5. Interval waktu perawatan (tp) $\mathrm{tp}=\frac{1}{n} \times \mathrm{r}=\frac{1}{1,148} \times 630=548,780 \mathrm{jam}$

6. Fungsi distribusi interval waktu kerusakan $\mathrm{F}(\mathrm{tp})$

$\mathrm{F}(549)=\Phi\left(\frac{6,308-6,108}{0,762}\right)=\Phi(0,262)$

$=0.6026[\ln (\mathrm{ti})=\ln (549)=6,308]$
7. Probabilitas interval waktu perawatan $(\mathrm{R}(\mathrm{tp}))$

$R(549)=1-0.6026=0.3974$

8. Waktu rata-rata terjadinya kerusakan bila perawatan dilakukan saat tp (M(tp))

$\mathrm{M}(549)=\frac{M T T F}{F(t p)}=\frac{482,517}{0.6026}=800,715$ jam.

\section{Kesimpulan}

Kesimpulan yang didapat dari penelitian mengenai Analisis Reliability Centered Maintenance (RCM) pada alat Rubber Tyre Gantry Crane (RTGC) sebagai berikut:

1. Dari Hasil Pengolahan data didapatkan nilai Mean Time To Failure (MTTF) adalah 482,517 dan nilai Mean Time To Repaire (MTTR) adalah 0,3

2. Dari hasil pengolahan data menggunakan metode FMEA maka didapatkan komponen kritis dari alat Rubber Tyre Gantry Crane 05 terdapat pada bagian Gantry yaitu sensor pin lock/unlock dengan efek kegagalan 
mengganggu kegiatan operasional (membuat terhenti operasi) dan harus dilakukan pemulihan atau penggantian komponen.

3. Dari hasil pengolahan data menggunakan metode RCM maka didapatkan interval waktu perawatan yang optimal untuk komponen sensor pin lock/unlock adalah 548,780 jam.

\section{Daftar Pustaka}

Abidin, M. R. (2019). Perencanaan Penjadwalan Perawatan Mesin Wheel Loader Dengan Pendekatan Reliability Centered Maintenance Di Pt. Swadaya Graha (Doctoral Dissertation, Universitas Muhammadiyah Gresik).

Adam, Tommy. Perencanaan Perawatan Mesin Thicknesser Dengan Metode Reliability Centered Maintenance (RCM) Dan Failure Mode And Effect Analysis (FMEA); Studi Kasus: Ud. Den Bagus. Diss. University Of Muhammadiyah Malang, 2019.

Ahmadi, Noor, and Nur Yulianti Hidayah. "Analisis Pemeliharaan Mesin Blowmould dengan Metode RCM di PT. CCAI." Jurnal Optimasi Sistem Industri 16.2 (2017): 167-176.

Alghofari, Ahmad Kholid, Much Djunaidi, and Amin Fauzan. "Perencanaan Pemeliharaan Mesin Ballmill Dengan Basis RCM (Reliability Centered Maintenance)." Jurnal Ilmiah Teknik Industri 5.2 (2006): 45-52.

Amalia, Sinar, Arief Subekti, and Priyo Agus Setiawan. "Perencanaan Kegiatan Perawatan dengan Metode RCM II (Reliability Centered Maintenance) dan Penentuan Persediaan Suku Cadang Pada Boiler Perusahaan Rokok." Seminar K3. Vol. 1. No. 1. 2017.

Ansori, N., Mustajib, M, I. 2013. Sistem Perawatan Terpadu. Yogyakarta : Graha Ilmu.

Ardhi, T. H. (2019). Minimasi Downtime Pada Unit Shore To Ship Dengan Metode Reliability Centered Maintenance (RCM) Di PT. Mitra
4. Berdasarkan perhitungan nilai probabilitas keandalan komponen sensor pin lock/unlock apabila melakukan perawatan sesuai dengan interval waktu perawatan yang telah dihitung maka didapatkan waktu ratarata kegagalan terjadi adalah 800.715 jam.

Sentosa Abadi. JISI: Jurnal Integrasi Sistem Industri, 6 (2), 127-133.

Aufar, A. N., Leksananto, K., \& Prassetiyo, H. (2014). Usulan Kebijakan Perawatan Area Produksi Trim Chassis Dengan Menggunakan Metode Reliability Centered Maintenance (Studi Kasus: PT. Nissan Motor Indonesia). Reka Integra, 2(4).

Bangun, Irawan Harnadi, Arif Rahman, and Zefry Darmawan. "Perencanaan Pemeliharaan Mesin Produksi Dengan Menggunakan Metode Reliability Centered Maintenance (RCM) II Pada Mesin Blowing Om (Studi Kasus: PT Industri Sandang Nusantara Unit Patal Lawang)." Jurnal Rekayasa dan Manajemen Sistem Industri 2.5 (2014): p997-1008.

Chandra, Muhammad Rizky Eka Permata. Analisis Keandalan Pada 542 Fn7 Finish Mill 2 Pabrik Tuban 1 PT. Semen Indonesia (Persero) Tbk. Dengan Pendekatan Metode Reliability Centered Maintenance. Diss. Institut Teknologi Sepuluh Nopember Surabaya, 2016.

Denur, D., Hakim, L., Hasan, I., \& Rahmad, S. (2017). Penerapan Reliability Centered Maintenance (RCM) pada Mesin Ripple Mill. JISI: Jurnal Integrasi Sistem Industri, 4(1), 27-34.

Dyadem . 2003. Panduan Untuk Failure Mode And Effect Analysis Untuk Otomotif, Dirgantara Dan Industri Manufaktur Umum. Ontario: CRC Press.

Gusti Ngr. Rai Usadha, Valeriana Lukitosari, Roficoh Nur Rohmah." Analisa Keandalan Pada Peralatan Unit 
Penggilingan Akhir Semen Untuk Menentukan Jadwal Perawatan Mesin (Studi Kasus Pt. Semen Indonesia Persero Tbk.) Seminar Nasional Matematika dan Aplikasinya, Surabaya, Universitas Airlangga, 21 Oktober 2017

Hakim, Legisnal. "Penerapan RCM Pada Sistem Distribusi Air Di Pdam Pasir Putih Pematangan Barangan Kabupaten Rokan Hulu." Jurnal Aptek 4.2 (2014): 129-140.

Kurniawan, Fajar. 2013 Manajemen Perawatan Industri; Teknik Dan Aplikasi; Implementasi Total Productive Maintenance, Preventive Maintenance Dan Reliability Centered Maintenance. Yogyakarta. Graha Ilmu.

Maulana, Irfan, Akhyar Ibrahim, and Darmein Darmein. "Analisa Kerusakan Komponen Undercarriage Excavator Hitachi Ex200 Pada Pt. Takabeya Perkasa Group Dengan Metode Fmea." Jurnal Mesin Sains Terapan 1.1 (2017): 32-37.

Muhsin, Ahmad, and Ichsan Syarafi. "Analisis Kehandalan dan Laju Kerusakan pada Mesin Continues Frying." Opsi 11.1 (2018): 28-34.

Palit, Herri Christian, and Winny Sutanto. Perancangan RCM untuk mengurangi downtime mesin pada perusahaan manufaktur aluminium. Diss. Petra Christian University, 2012.

Pranoto, Hadi.'Reliability Centered Maintenance" Mercu Buana Mitra Wacana Media, 2015

Putra, Eko Lisysantaka Rusma. 2011. Artikel Reliability Centered Maintenance (RCM) Https://Www.Scribd.com (diakses pada tanggal 30 September 2019).

Rosih, Akhmad Raunaq, Mochamad Choiri, and Rahmi Yuniarti. "Analisis risiko operasional pada departemen logistik dengan menggunakan metode FMEA." Jurnal Rekayasa dan Manajemen Sistem Industri 3.3 (2015): p580-591.

Saputra, Denny Randiana Firda, Yudi Sukmono, and Lina Dianati Fathimahhayati. "Analisis Reliability Pada Mesin Fan Mill Unit 1 di PT Cahaya Fajar Kaltim." Dinamika: Jurnal Ilmiah Teknik Mesin 10.1 (2018): 1-8.

Soleh, S., Bandriyana, B., Djajono, H. S. W. I., \& Mm, I. (2013). Analisis Dan Perancangan Sistem Informasi Preventive Maintenance Dengan Modularity Pada Pt. Multazam Mitra Prima (Doctoral Dissertation, Binus).( 2012-2-00251-Tisi Bab2001)

Sukopriyatno, Adi, Sri Rahayuningsih, and Ana Komari. "Perancangan Penjadwalan Perawatan Mesin Bubut Dengan Metode Reliability Centered Maintenance (Rcm) Di Bengkel Pemesinan Smk Negeri 1 Kediri." JURMATIS: Jurnal Ilmiah Mahasiswa Teknik Industri 1.1 (2019).

Susanto, Agustinus Dwi, and Hery Hamdi Azwir. "Perencanaan Perawatan Pada Unit Kompresor Tipe Screw Dengan Metode RCM di Industri Otomotif." Jurnal Ilmiah Teknik Industri 17.1 (2018): 21-35.

Utomo, R.W. (2018). Perencanaan Perawatan Mesin Pump 107 Dengan Metode Reliability Centered Maintenance (RCM) Di PT. Petrokimia Gresik. Jurnal Energi dan Teknologi Manufaktur (JETM), 1. 